\title{
Ethical challenges to medical assistance at sea
}

\author{
Giovanna Ricci ${ }^{\mathrm{a}}$, Isabel Pirillo ${ }^{\mathrm{b}}$, Francesco Amenta ${ }^{\mathrm{b}, \mathrm{c}, *}$

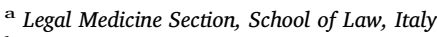 \\ b Centre of Telemedicine and Telepharmacy, University of Camerino, 62032 Camerino, Italy \\ ${ }^{\mathrm{c}}$ Research Department International Radiomedical Centre (CIRM), 00144 Rome, Italy
}

\section{A R T I C L E I N F O}

\section{Keywords:}

Health care for specific diseases/groups

Emergency medicine

Ethics

Health workforce

Occupational health

\begin{abstract}
A B S T R A C T
Illnesses and accidents occur on board seagoing vessels. In these cases, lacking medical or paramedical personnel, the ship's captain or an officer delegated by him provides medical care and in general asks for medical advice by means of telecommunication systems. The situation is in general different on passenger ships, on board of which are doctors or paramedical personnel. Telemedicine services for ships without medical facilities are provided by the Telemedical Assistance Services (TMAS). The captain is always responsible for medical care and final decisions regarding health of seafarers. Full responsibility for the diagnosis and prescription of treatments belongs to the doctor on board or to the TMAS physician. The physician on the ship or at TMAS should protect the privacy of patients. The telemedicine services and in particular the doctor-patient relationship on vessels present ethical and legal issues that are not the same as those experienced ashore. These issues are discussed and some possible solutions to improve patient-physician relationships are suggested.
\end{abstract}

\section{Introduction}

For centuries seafarers did not have medical assistance when at sea, except for naval vessels which from the 16th century often carried medical personnel on board. Seagoing vessels could remain at sea for days or weeks before reaching a port. Using his knowledge of hygiene and medicine, the captain of the ship was in charge of the treatment of diseases and the health protection of the crew. The possibility of providing medical assistance to ships via telecommunication systems became possible with the development of radiotelegraphy by Guglielmo Marconi in 1897, the construction of coastal radio stations and the introduction of radio equipment on ships. The first license for a radio medical service to ships was issued on November 18, 1920 to the Seamen's Church Institute in New York. The first experience of enlargement of radio medical assistance from a domestic to an international level occurred in Italy in 1935, with the constitution of the Centro Internazionale Radio Medico (International Radio Medical Centre, CIRM) [1,2]. For more than 80 years, several radio medical services have been operational, starting by using radio signals and Morse code, evolving through telephones to full blown telemedicine solutions.

In addition to all the challenges facing telemedicine users and providers on land, there are also problems to be tackled at sea. Technological limitations are obvious, but there are also significant medical challenges $[1,2]$. The officer responsible for medical duties on board is the person in charge of the patient. Normally, this is the captain or the first mate. The technical and medical skills of the medical officers on ships vary considerably, as do the languages and cultural backgrounds. The majority of merchant ships do not carry a medical doctor on board, whereas the situation in general is different for passenger ships which have doctors or adequately trained paramedics. In the case of accidents or diseases on board, the captain of the ship may ask for help from a Telemedical Assistance Service (TMAS). If the captain fails to do so, he may be responsible for the omission. Telemedicine represents the most realistic perspective for offering at least a minimum of medical care to seafarers at sea [1-3].

Several international conventions have regulated radio medical consultations in the past and contemporary maritime telemedical services. In 1958 the International Labor Organization (ILO) issued a Convention requiring all seafaring nations to have a service for radio medical advice to ships [4]. The ILO Convention of 1987 [5], is another important document on this topic and specifies that sailors should have health protection and access to medical care. In 1992, the European Union issued Council Directive 29, 1992 with the same imperative [6]. The most recent regulation on the topic is the International Maritime Organization (IMO) Circular MSC/Circ.960 of 20 June 2000 entitled "Medical Assistance at Sea" [7]. This circular considers that medical assistance at sea is an integral part of rescue as defined by the International Convention on Maritime Search and Rescue (SAR) [8], thereby recognizing the importance of the role of Telemedical Assis-

\footnotetext{
* Corresponding author at: Centro di Telemedicina e Telefarmacia, Università di Camerino, 62032 Camerino, Italy.

E-mail address: francesco.amenta@unicam.it (F. Amenta).
} 
Table 1

Main international regulations on delivery of medical assistance at sea.

\begin{tabular}{clll}
\hline Year & Issuing organization & Title & Reference \\
\hline 1958 & $\begin{array}{l}\text { R106 - Medical Advice at Sea } \\
\text { Recommendation, 1958 (No. 106) } \\
\text { C164 - Health Protection and } \\
\text { Medical Care (Seafarers) } \\
\text { Convention, 1987 (No. 164) }\end{array}$ & $\begin{array}{l}\text { International Labor } \\
\text { Organization (ILO) } \\
\text { International Labor } \\
\text { Organization (ILO) }\end{array}$ & 5 \\
$\begin{array}{l}\text { Directive 92/29/EEC Medical } \\
\text { treatment on board vessels } \\
\text { Medical Assistance at Sea. Circular } \\
\text { MSC/Circ.960. IMO London, 2000 }\end{array}$ & $\begin{array}{l}\text { European Economic } \\
\text { Community } \\
\text { International } \\
\text { Maritime } \\
\text { Organization (IMO) }\end{array}$ & 6 \\
\hline
\end{tabular}

tance Services (TMAS), and of Maritime Radio Communications for providing care to people who are ill or injured at sea [7]. Table 1 summarizes the main international regulations on medical assistance at sea.

The purpose of this paper is accordingly to consider major issues regarding the practice of telemedicine at sea. This is done by considering in turn medical ethics at sea; medical aspects of fitness to board; the role of the physician; informed consent; and privacy.

\section{Medical ethics at sea}

High quality medical assistance at sea has several ethical implications which have not been extensively discussed in the literature. An important consideration is whether the fundamental ethical principles of maritime medicine are the same as for medicine in general or if telemedicine at sea faces different ethical issues. Health protection should not be limited to the treatment of sick or injured sailors, but must include all those measures of a preventive nature such as health promotion and education programs. The ILO Convention of 1987, art. 9 states that: "If one ship does not have a doctor, one or more people should be designated with specific duties and responsibility, such as medical care and administration of drugs as part of their normal functions. 'Moreover, a person responsible for medical assistance on board..., who is not medical doctor', shall have satisfactorily completed a course, theoretical and practical in medical skills, recognized by the competent authority" [5].

While the protection of both passengers and crew is the captain's duty, it is advisable to consult a TMAS to assess the state of health of a person on a ship without a doctor. The maritime doctor may face particularly complicated health choices but also decisions that could be problematic, such as quarantines and landings, and must always act in accordance with international/national regulations as well as medical ethics [3]. The ethics of maritime medicine can be defined as the general principles of medical ethics, but with more complexities. In reality the patient is in a remote location [3] and the person providing medical assistance may not have the advanced knowledge necessary to put a doctor's prescription into practice.

\section{Medical aspects of fitness to board}

The process of assessment of health of the individual seafarer begins with the assessment of medical fitness to board. Working on board ships can have serious professional consequences for sailors. Preventive medical examination is held according to international rules implemented in several cases by national laws. A physician should determine whether a person is ready to board the ship or whether he or she is unfit for the voyage that could endanger him/her and other crew-members [9]. The health condition of sailors is listed in national laws [10]. Another problem not yet addressed by regulations but nonetheless important is the psychological condition of seafarers who experience long periods away from family. The psychological state of seafarers should be assessed by the standard examinations. This would avoid very serious problems such as suicides by seafarers, that have a significantly higher incidence compared to people living and working ashore [11-13].

\section{The role of physicians}

In providing health and medical care to seafarers at sea, the fundamental role of the medical doctor (teledoctor) is to actively listen to the patient during consultation. The doctor should provide the most appropriate treatment and medical care without imposing his moral, religious or political views and without discrimination with respect to age, race, nationality or social status of sailors [14]. Difficulties in following these principles are obvious. The doctor has never seen the patient, and most probably never will. Normally he or she will not even speak to the patient, but to the captain or the officer in charge of the treatment. Hence, in the majority of cases the physician has no direct interaction with the patient. On the other hand, although the most recent international regulations confer full responsibility for the diagnosis and prescription of treatment on the TMAS doctor, these also give the captain responsibility for examining the patient, administering treatment and the final decisions [7]. The principle of leaving the final decisions to the ship's captain is appropriate in most situations, but it may be questioned whether the captain has sufficient competence to judge relevance with regard to a medical problem.

\section{Informed consent}

In general, no one, whether medically qualified or not, can examine anyone else for health reasons or give any form of treatment, without explicit informed consent. Failing to obtain this consent may result in civil liability and may even constitute a criminal offence. Telemedicine can offer solutions for treatment of remote patients such as seafarers, but also poses challenges related to the safeguarding of patients' rights, including problems related to informed consent. As for all patients, seafarers must be informed about their health status and, if it is positive, they need to accept medical decisions [15]. This should remain true if treatment is prescribed by a doctor present on board or by using telemedicine. The only alternatives are the presumption of consent or a state of necessity. Each crew member should be informed of their right to give or refuse consent to examination and treatment, as well as other rights if their condition makes this possible, without any obligation to explain or justify a possible negative decision. Basic information such as what and why a proposed treatment or an examination is necessary should always be given, making sure that explanations are simple, clear and understandable, as well as ensuring that consent is explicit. Although the practice of asking patient consent is recommended in medical books for ships [16], the extent to which this practice is common and how it is put into practice is questionable.

Questions that need to be answered and hopefully regulated are the content of the informed consent, the form it takes and whose responsibility it is to gain this consent $[16,17]$. As a working hypothesis it can proposed that in the course of basic medical procedure, it is not necessary for the patient to sign a document to indicate consent, except in particular situations or when disputes about this consent might occur. As a precaution it would be advisable to have another person present as a witness when the patient consents. An additional complication in maritime telemedicine practice is that teleconsultations are generally recorded. Express, informed and fully voluntary consent is required before a patient can be recorded unless such consent is related to patient co-operation in diagnostic or therapeutic procedures. Specific initiatives such as campaigns for explaining the need for and ethical bases of informed consent given by seafarers in case of diseases or injuries on board ships should be promoted. This will increase awareness among seafarers regarding their rights when sick, and will contribute to improve the quality of medical care delivered to them. 


\section{Privacy}

Patients must give their health data to the medical doctor. This information is confidential and should not be disclosed; otherwise the physician may be punished for violation of confidentiality, based on both criminal laws and codes of medical ethics. Since the beginning of the history of medicine, confidentiality has been at the heart of medical ethics. In modern times Codes of Medical Ethics were introduced at the international and national levels. The principle common to these Codes is that a physician should preserve absolute confidentiality regarding all he or she knows about the patient, even after the patient's death [18]. Telepractitioners, and healthcare facilities and telecommunication service providers may face action where confidential medical information is sent to persons not within the ambit of a patient's consent. It is important to bear in mind the legal and ethical duties regarding confidentiality when tele-health networks are implemented. It should also be noted that the healthcare providers may be liable in tort for any deterioration of a patient's condition that occurs as a result of the improper disclosure of records [19].

The conversation or the transfer of information between the physician and a patient, or other crew-members, is often heard by people who do not play any role in the health care process, and these dialogues can also be recorded. In this case, the main duty of the physician is to take action and cure the health problems of the sailors. The dialogue between the physician and a patient plays a key role in choosing the best treatment to pursue, but unfortunately only rarely does the doctor speak with patients in maritime telemedicine practice. Theoretically, the diagnosis and cure prescribed should be discussed only with those involved in the treatment of the patient but, unfortunately, it is often difficult to ensure full privacy in these types of conditions. All information about health, disease onset, diagnosis, prognosis and treatment, as well as any other information regarding a sick or injured patient must be kept confidential [15]. The many actors involved (captain of ship, maritime authorities, and shipping company support staff) may find it extremely difficult to keep adequate levels of privacy protection in maritime telemedicine practice. According to the laws in force, confidential information cannot be given to other people without the approval of the sailors. Moreover, if it is really necessary, medical data can only be shared, for the purpose of treatments or after the explicit consent of the patient, between health professionals, and there should be appropriate means to manage and archive data [20].

\section{Conclusions}

The doctor-patient relationship has evolved relatively recently into a therapeutic alliance, which means that the patient participates more actively by giving to the doctor all the information necessary to make a correct diagnosis and formulate a treatment plan. However, the physician should respect the patient's refusal of treatment. Since informed consent and computerized processing of health data may cause problems, especially in the case of missing data, the doctor would not have a full medical history of the patient. Another critical point of telemedicine is the creation of a contractual relationship between the doctor and the patient, which is linked to the problem of digital signature, the electronic document and the bargaining at a distance. This issue becomes even more complex because of the lack of specific regulatory provisions, in the context of a cultural setting that remains wary of widespread use of technology.

The central theme of this paper whether the fundamental ethical principles of medicine are the same as those applicable to telemedicine or if new ethical issues have arisen. The answer is that there are certain situations peculiar to telemedicine. Difficult conditions in the exercise of telemedicine make the implementation of some of the fundamental ethical rules more complicated: the cure; the distance of the patient; the information mediated, the different languages spoken; and the problems concerned with not being able to make visits and diagnosis. In conclusion, it can be said that maritime telemedicine, when the patient is remote from the doctor makes the doctor- patient relationship more difficult to standardize in strict compliance with the fundamental ethical principles of the doctor-patient relationship.

\section{Acknowledgements}

The present study was supported by the $0.5 \%$ funds to Centro Internazionale Radio Medico (CIRM).

\section{References}

[1] W.H.G. Goethe, Medical care on ships without a doctor. Radio medical advice, in: W.H.G. Goethe, E.N. Watson, D.T. Jones (Eds.), Handbook of Nautical Medicine. Springer, Berlin, 1984, pp. 53-65.

[2] F. Amenta, A. Dauri, N. Rizzo, Organization and activities of the International Radio Medical Centre (CIRM), J. Telemed. Telecare 2 (1996) 125-131.

[3] G. Ricci, I. Pirillo, C. Rinuncini, F. Amenta, Medical assistance at the sea: legal and medico-legal problems, Int Marit. Health 65 (2014) 205-209, http://dx.doi.org/10. 5603/IMH.2014.0039.

[4] International Labour Organization (ILO), Medical Advice at Sea Recommendation No. 106. Geneva, 1958.

[5] International Labour Organization (ILO), Health Protection and Medical Care (Seafarers) Convention No. 164. Geneva, 1987.

[6] European Economic Community. Directive 92/29/EEC, Medical treatment on board vessels. Brussels, 1992.

[7] International Maritime Organization (IMO), Medical Assistance at Sea (Circular MSC/Circ.960), IMO, London, 2000.

[8] International Convention on Maritime Search and Rescue (SAR), Adoption: 27 April 1979; Entry into force: 22 June 1985 〈http://www.imo.org/About/Conventions/〉 ListOfConventions/Pages/International-Convention-on-Maritime-Search-andRescue-\%28SAR\%29.aspx (accessed 14 May), 2015.

[9] Guidelines on the medical examinations of seafarers, International Labour Office, Sectoral activities Programme; International Migration Organization, ILO, Geneva, 2013.

[10] Textbook of Maritimes Medicine, Second edition, 〈http://textbook.ncmm.no/〉 component/content/category/41-8-the-maritime-physician. (accessed 14 March 2014), 2013.

[11] B. Loddé, D. Lucas, R. Pougnet, D. Jegaden, J.A. Bronstein, J.D. Dewitte, Deaths on board: medical and legal implications for the maritime physician, Int Marit. Health 61 (2010) 24-27.

[12] I. Grappasonni, F. Petrelli, F. Amenta, Deaths on board ships assisted by the Centro Internazionale Radio Medico in the last 25 years, Travel Med Infect. Dis. 10 (2012) 186-191, http://dx.doi.org/10.1016/j.tmaid.2012.06.006.

[13] V. Rafnsson, A. Kristbjornsdottir, Increased cardiovascular mortality and suicide after methyl chloride exposure, Am. J. Ind. Med. 57 (2014) 108-113, http://dx.doi. org/10.1002/ajim.22243.

[14] Minimum requirements for the medical examination of seafarers, ILO. 〈http:// www.ilo.org/public/english/dialogue/sector/techmeet/ilowho97/meden6.htm〉 Heading51. (accessed 23 March 2014), 1997.

[15] Convention on Human Rights and Biomedicine of the Council of Europe, Preamble A, Chapter II art. 5, 〈http://www.iss.it/binary/coet/cont/ConvOviedo. 1128329819.pdf $\rangle$, (accessed 23 March 2014), 1996.

[16] WHO Library Cataloguing-in-Publication Data. International Medical Guide for Ships: Including the Ship's Medicine Chest. 3rd ed.

[17] I. Dreezen, Telemedicine and informed consent, Med Law 23 (2004) 541-549.

[18] J.C. Thomas, M. Sage, J. Dillenberg, V.J. Guillory, A Code of Ethics for Public Health, Am. J. Public Health 92 (2002) 1057-1059.

[19] S.F.S. Coles, Telemedicine: the Rise of Digital Healthcare, FT Pharmaceuticals \& Healthcare Publishing, London, 1995.

[20] D. Malicier, A. Miras, P. Feuglet, P. Faivre, La responsabilité médicale, données actuelles, Editions Eska, Lyon, 1999. 